\title{
누는 1
}

[2012-12-WD-001]

\section{풍력발전기의 에너지 비용 산출에 대한 고찰}

정태영*, 문석준, 임채환

\section{A Study on the Estimation Model of Cost of Energy for Wind Turbines}

Taeyoung Chung*, Seokjun Moon and Chaewhan Rim

Abstract Large offshore wind farms have actively been developed in order to meet the needs for wind energy since the land-based wind farms have almost been fully developed especially in Europe. The key problem for the construction of offshore wind farms may be on the high cost of energy compared to land-based ones. NREL (National Renewable Energy Laboratory) has developed a spreadsheet-based tool to estimate the cost of wind-generated electricity from both land-based and offshore wind turbines. Component formulas for various kinds and scales of wind turbines were made using available field data. In this paper, this NREL estimation model is introduced and applied to the offshore wind turbines now under designing or in production in Korea, and the result is discussed.

Key words Wind Turbine(풍력발전기), Cost of Energy(에너지 비용), Prediction Model(추정모델), Balance of Station(주변장치)

(접수일 2012. 9. 6, 수정일 2012. 10. 22, 게재확정일 2012. 10. 22)

* 한국기계연구원 시스템다이나믹스연구실 (Dept. of System Dynamics, KIMM )

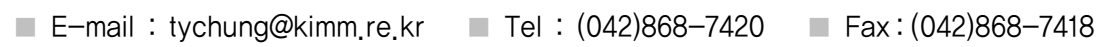

\section{1. 서 론}

풍력발전에 대한 미래 수요가 큰데 비하여 대규모 육상 풍 력단지의 조성을 위한 대지확보가 어려워 이의 대안으로 해 상 풍력단지가 활발히 개발되고 있다. 해상은 육상보다 바람 의 질이 좋고 상대적으로 대규모 풍력단지를 구성할 수 있다 는 장점이 있으나, 해상 풍력발전은 육상 풍력발전에 비하여 제작 및 설치비용이 많이 들고 보수 및 유지 측면에서도 불리 하다. 문제는 해상 풍력발전의 경제성이다. 풍력발전의 경제 성 분석과 관련하여 발표된 연구 및 문헌은 많지 않은 편이
다. 국내에서는 대관령 풍력단지의 풍속의 분포 및 풍력발전 량을 검토하고 대관령 풍력 발전의 경제성을 분석한 논문 ${ }^{(1)}$ 이 있으며, 국외에서의 관련문헌으로는 육상과 해상의 풍력발전 의 경제성을 분석한 $\mathrm{EWEA}$ (유럽풍력에너지협회)의 보고서 ${ }^{(2)}$ 가 있다. 또한 미국의 DOE/NREL에서는 현재 가장 보편적이 고 일반적인 형태인 3-날개의 수평축 풍력발전기에 대하여 실 제 축적된 데이터로부터 구성품별 축척모델을 만들어서 크기 와 형상의 변화가 에너지 비용에 얼마나 영향을 주는가를 추정 할 수 있는 spreadsheet 형태의 예측 모델을 개발하였다 ${ }^{(3)}$ 본 연구에서는 NREL의 연구결과로서 발표된 축척에 따른 풍 
력발전 비용 추정모델을 소개하고, 이를 국내외 육상 및 해상 풍력발전시스템에 적용하여 그 결과를 분석하였다.

\section{2. 에너지 비용의 산출}

에너지 비용으로 보통 사용되는 것은 풍력터빈의 전 생애 동안의 자산투자비용, 운영, 수리 및 유지를 위한 비용 등을 포함하는 생산비용을 연간 수명기간으로 나눈 균등화된 에너 지비용(Levelized Cost of Energy)이며, 식으로는 다음과 같 이 주어진다.

$$
\mathrm{COE}=(\mathrm{FCR} \times \mathrm{ICC}) / \mathrm{AEP}_{\text {net }}+\mathrm{AOE}
$$

$$
\begin{aligned}
& \text { 여기서, } \\
& \mathrm{COE}=\text { 에너지 비용 }(\$ / \mathrm{kWh}) \\
& \mathrm{FCR}=\text { Fixed Charge Rate }(1 / \mathrm{yr}) \\
& \mathrm{ICC}=\text { 초기자산비용 } \\
& \mathrm{AEP}_{\text {net }}=\text { 년간 에너지 순생산량 }(\mathrm{kWh} / \mathrm{yr})
\end{aligned}
$$

$\mathrm{FCR}$ 은 자산비용을 감당하기위해 매년 필요한 금액으로, 부채의 이자 및 증권의 배당, 기타 고정 부담경비를 포함한 다. 현재 예측모델에서 $\mathrm{FCR}$ 은 건설을 위한 차입금, 차입을 위한 비용, 부채이자 및 증권배당, 감가상각, 수익세, 재산세 와 보험료 등을 포함하며 0.1158/year로 설정되었다. $\mathrm{ICC}$ (초 기자산비용)은 터빈계의 비용과 그 외의 주변장치(balance of station)비용의 합이다. 건설자금이나 융자를 위한 비용 (financing fee)은 별도로 계산되어 FCR에 포함된다. AEPnet (년간 순 에너지생산량, net Annual Energy Production)은 주어진 년 평균풍속을 기준으로 하여 산출된 에너지생산량을 계산한 것이다. 총에너지생산량에 로터의 파워계수, 기계적 전기적 변환에 따른 손실, 날개표면의 더러워짐에 의한 손실, 배열 손실과 기계의 적용성과 같은 요인에 의해 조정된다. 년 순 에너지생산량을 계산하기위해 사용된 모델은 5 장에서 간 략하게 기술하였다.

$\mathrm{AOE}$ (년 운용경비)는 토지 및 해역 임대비, 균형화된 O\&M비 용과 균형화된 대체비(LRC, Levelized Replacement/Overhaul Cost)를 포함하며, 다음 식으로 계산 된다.

$$
\mathrm{AOE}=\mathrm{LLC}+(\mathrm{O \& M}+\mathrm{LRC}) / \mathrm{AEP}_{\text {net }}
$$

여기서,

$\mathrm{LLC}=$ 년간 토지 및 해역 임대비용 (Land Lease Cost)

$\mathrm{O} \& \mathrm{M}=$ 균형화된 보수유지비용 (Levelized O\&M Cost)

$\mathrm{LRC}=$ 균형화된 대체비용

(Levelized Replacement/Overhaul Cost)

\section{3. 구성품의 비용추정 모델}

NREL의 비용추정모델 ${ }^{(3)}$ 은 간단한 축척관계식을 이용하여 크기와 모양이 다른 풍력터빈과 그 구성품의 비용을 예측하는 spreadsheet 기반의 도구이다. 이 모델은 모든 가능성이 있는 풍력터빈형상을 대상으로 하는 것이 아니라 지금 현재 풍력 산업에서 가장 많이 사용되고 있는 three-bladed, upwind, pitch-controlled, variable speed의 특성을 갖는 터빈을 대 상으로 한다. 예측모델 속의 공식들은 초기 버전으로 매우 단 순한 편이다. 대부분의 경우 비용 추정식들은 로터 직경, 터 빈의 정격출력, tower 높이, 혹은 이들의 조합의 함수이다. 비용예측결과는 일관성을 위하여 2002년 달러의 기준으로 추정되었다. 2002년이 아닌 해의 비용데이터들은 예측모델 을 만들기 전에 모두 2002년 달러기준으로 바꾸었다. 비용데 이터는 구성품의 생산이 이미 완숙기에 있다는 가정과 함께, $50 \mathrm{MW}$ 의 풍력단지를 기준으로 하였다.

풍력터빈의 주요한 구성품은 다음과 같이 분류되며, 이의 비용추정 모델 식을 정리하면 Table 1과 같다. Table 1에서 $\mathrm{R}$ 과 $\mathrm{D}$ 는 각각 로터의 반경과 직경을 나타내며, 단위는 $\mathrm{m}$ 를 사용한다.

블레이드의 비용추정모델은 재료비, 인건비 및 이윤 및 오 버헤드로 구성되어 있는데 Table 1에 주어진 식의 분자의 첫 째 항이 재료비, 둘째 항이 인건비를 나타내며 분모의 0.28 은 이윤 및 오버헤드를 나타낸다. Table 1 에서 보는 바와 같이 블레이드와 tower의 경우에는 baseline model과 advanced model이 주어져 있는데, advanced model은 특별히 새로운 재료와 신기술이 적용된 경우에 사용되는 것으로 한다. 풍력터 
빈 동력계를 구성하는 기어박스, 발전기 및 main frame은 특 성에 따라 Three-Stage Planetary/Helical with High-Speed generators, Single-Stage Drive with Medium-Speed
Generators, Multi-Path Drive with Multiple Generators, Direct Drive Generators 중에서 해당되는 형식을 선택하여 비용을 추정한다.

Table 1. Formula for wind turbine components

\begin{tabular}{|c|c|c|c|}
\hline \multicolumn{3}{|l|}{ Components } & Cost formulas $(\$)$ \\
\hline \multirow{4}{*}{ Rotor } & Blades & $\begin{array}{l}\text { Baseline } \\
\text { Advanced }\end{array}$ & $\begin{array}{l}{\left[\left(0.4019 \times R^{3}-955.24\right)+2.7445 \times R^{2.5025}\right] /(1-0.28)} \\
{\left[\left(0.4019 \times R^{3}-21051\right)+2.7445 \times R^{2.5025}\right] /(1-0.28)}\end{array}$ \\
\hline & \multicolumn{2}{|l|}{ Hub } & $\begin{array}{l}\text { Hub mass } \times 4.25 \\
=(0.954 \times \sin \text { gle blade mass }+5680.3) \times 4.25 \\
\text { where } \\
\text { single blade mass }=0.1452 \times R^{2.9158} \text { for } B L \\
\text { single blade mass }=0.4948 \times R^{2.53} \text { for } \text { Advancd }\end{array}$ \\
\hline & \multicolumn{2}{|c|}{ Pitch mechanisms \& bearings } & $2.28 \times\left(0.2106 \times D^{2.6578}\right)$ \\
\hline & \multicolumn{2}{|c|}{ Spinner, Nose cone } & $\begin{array}{l}\text { Nose cone mass } \times 5.57 \\
=(18.5 \times D-520.5) \times 5.57\end{array}$ \\
\hline \multirow{11}{*}{$\begin{array}{l}\text { Drive } \\
\text { train, Nacelle }\end{array}$} & \multicolumn{2}{|c|}{ Low speed shaft } & $0.01 \times D^{2.887}$ \\
\hline & \multicolumn{2}{|l|}{ Bearings } & $\begin{array}{l}2 \times \text { Bearing Mass } \times 17.6 \\
=2 \times(D \times 8 / 600-0.33) \times 0.0092 \times D^{2.5}\end{array}$ \\
\hline & Gearbox & $\begin{array}{l}\text { Three-Stage } \\
\text { Single-Stage } \\
\text { Multi-Path Drive } \\
\text { Direct Drive }\end{array}$ & $\begin{array}{l}16.45 \times \text { Machine Rating }^{1.249} \\
74.1 \times \text { Machine Rating }^{1.0} \\
15.26 \times \text { Machine Rating }^{1.249} \\
0\end{array}$ \\
\hline & \multicolumn{2}{|c|}{ Mechanical brake, HS coupling, etc } & $1.9894 \times$ Machine Rating -0.1141 \\
\hline & Generator & $\begin{array}{l}\text { Three-Stage } \\
\text { Single-Stage } \\
\text { Multi-Path Drive } \\
\text { Direct Drive }\end{array}$ & $\begin{array}{l}65 \times \text { Machine Rating } \\
54.73 \times \text { Machine Rating } \\
48.03 \times \text { Machine Rating } \\
219.33 \times \text { Machine Rating }\end{array}$ \\
\hline & \multicolumn{2}{|c|}{ Variable speed electronics } & $79 \times$ Machine Rating \\
\hline & \multicolumn{2}{|c|}{ Yaw drive $\&$ bearings } & $2 \times\left(0.0339 \times D^{2.964}\right)$ \\
\hline & Main frame & $\begin{array}{l}\text { Three-Stage } \\
\text { Single-Stage } \\
\text { Multi-Path Drive } \\
\text { Direct Drive }\end{array}$ & $\begin{array}{l}9.489 \times D^{1.953}+0.125 \times\left(2.233 \times D^{1.953}\right) \times 8.7 \\
303.96 \times D^{1.067}+0.125 \times\left(1.295 \times D^{1.953}\right) \times 8.7 \\
17.92 \times D^{1.672}+0.125 \times\left(1.721 \times D^{1.953}\right) \times 8.7 \\
627.28 \times D^{0.85}+0.125 \times\left(1.228 \times D^{1.953}\right) \times 8.7\end{array}$ \\
\hline & \multicolumn{2}{|c|}{ Electrical connections } & $40 \times$ Machine Rating \\
\hline & \multicolumn{2}{|c|}{ Hydraulic, cooling system } & $12 \times$ Machine Rating \\
\hline & \multicolumn{2}{|c|}{ Nacelle Cover } & $11.537 \times$ Machine Rating +3849.7 \\
\hline \multicolumn{3}{|c|}{ Control, Safety system, Condition monitoring } & 35,000 \\
\hline Tower & \multicolumn{2}{|l|}{$\begin{array}{l}\text { Baseline } \\
\text { Advanced }\end{array}$} & $\begin{array}{l}(0.3973 \times \text { swept area } \times \text { hubheight }-1414) \times 1.5 \\
(0.2694 \times \text { swept area } \times \text { hubheight }+1779) \times 1.5\end{array}$ \\
\hline
\end{tabular}

Table 2. Input parameters of wind turbines

\begin{tabular}{l|c|c|c|c|c}
\hline Design parameter & NREL & Model A & NREL & Model B \\
$3.0 \mathrm{MW}$ & $2.0 \mathrm{MW}$ & $3.0 \mathrm{MW}$ & 3,000 \\
\hline Rated power $(\mathrm{kW})$ & 1,500 & 2,000 & 3,000 & 91.3 & 5,000 \\
\hline Rotor diameter $(\mathrm{m})$ & 70 & 88 & 90 & 80 \\
\hline Hub height $(\mathrm{m})$ & 65 & 80 & 80 & 3 3-stage & 3-stage \\
\hline Gear type & 3-stage & 3-stage & offshore & offshore \\
\hline Installed location & land & land & & offshore \\
\hline
\end{tabular}


Table 1에서 소개된 모델링을 적용하여 현존하는 몇 개의 MW급 풍력터빈(모델 및 입력제원은 Table 2 참조)에 대하여 제작비용을 추정하였다. Table 2에서 Model A와 Model B는 국내 제작사 제품이다. 블레이드 및 hub와 타워의 경우 두 개의 추정모델(Baseline과 Advanced model) 중에서 Baseline 추정모델을 사용하였으며, 결과는 Table 3 과 같이 요약된다. 추정된 구성품별 비용이 전체에서 차지하는 비중을 계산하고 이를 다른 참고문헌에서 예로 제시한 구성비와 비교하여 보 았다. 주요한 분석내용은 다음과 같다.

- 풍력터빈의 제작비용은 $\mathrm{kW}$ 당 $\$ 660$ 800이며, 풍력터빈 의 정격출력의 크기에 따라 크게 변화하지 않는다.

- 비용상 중요한 구성품은 블레이드(15 20)\%, gear box (13 18)\%, Tower(14 18)\%, 발전기 및 variable speed electronics 각각 $10 \%$ 이내이다.

- 구성비 중에서 참고문헌 [4]와 비교하여 가장 큰 차이를 보 이는 것은 타워의 구성비이다. 참고문헌 [4]에서 발췌한 구 성비를 보면 타워의 구성비가 전체의 $29 \%$ 정도로서 NREL
의 추정모델에서 추정한 구성 비율 약 $16 \%$ 에서 크게 벗어 난다. Fig. 1은 참고문헌 [4]에서 언급하고 있는 Repower 사의 $5 \mathrm{MW}$ 터빈에 대한 자료이다.

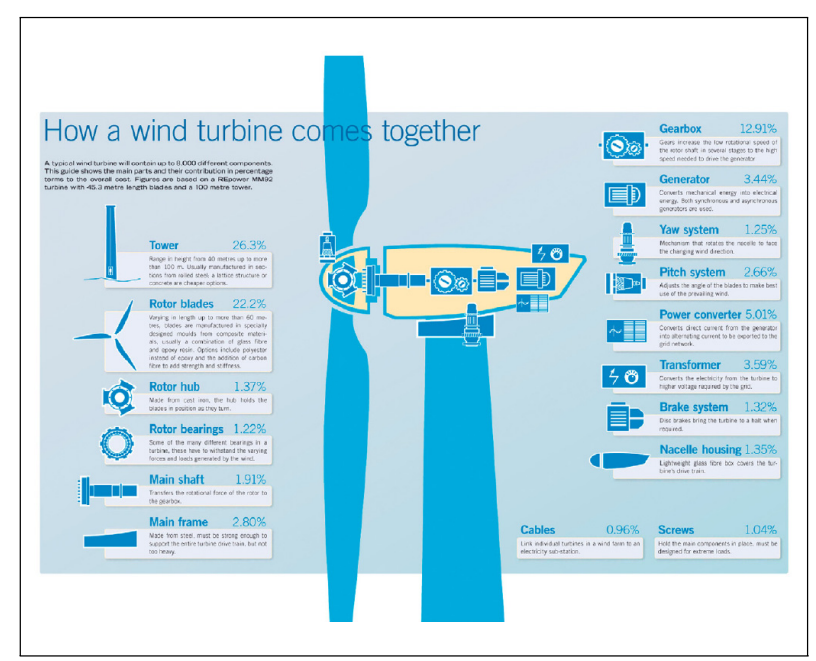

Fig. 1 Cost ratio for components of Repower 5 MW turbine ${ }^{(4)}$

Table 3. Cost prediction of wind turbine components(Costs: $\$ 1,000$ )

\begin{tabular}{|c|c|c|c|c|c|c|c|c|c|c|c|c|}
\hline \multirow{2}{*}{\multicolumn{2}{|c|}{ Components }} & \multicolumn{2}{|c|}{ NREL $1.5 \mathrm{MW}$} & \multicolumn{2}{|c|}{ Model A $2.0 \mathrm{MW}$} & \multicolumn{2}{|c|}{ NREL 3.0 MW } & \multicolumn{2}{|c|}{ Model B 3.0 MW } & \multicolumn{2}{|c|}{ OC3 5.0 MW } & \multirow{2}{*}{$\begin{array}{c}\text { ref.(6) } \\
5.0 \mathrm{MW}(\%)\end{array}$} \\
\hline & & costs & $\%$ & costs & $\%$ & costs & $\%$ & costs & $\%$ & costs & $\%$ & \\
\hline \multirow{5}{*}{ Rotor } & Blades & 151 & 15.24 & 287 & 18.27 & 305 & 15.26 & 318 & 15.61 & 779 & 19.37 & 24.85 \\
\hline & Hub & 43 & 4.34 & 61 & 3.88 & 63 & 3.15 & 65 & 3.19 & 128 & 3.18 & 1.53 \\
\hline & Pitch mechanisms \& bearings & 38 & 3.83 & 71 & 4.52 & 75 & 3.75 & 78 & 3.83 & 184 & 4.57 & 2.98 \\
\hline & Spinner, Nose cone & 4 & 0.40 & 6 & 0.38 & 6 & 0.30 & 7 & 0.34 & 10 & 2.49 & - \\
\hline & Sub sum & 237 & 23.92 & 424 & 26.99 & 450 & 22.51 & 467 & 22.93 & 1,100 & 27.35 & 29.36 \\
\hline \multirow{12}{*}{$\begin{array}{l}\text { Drive } \\
\text { train, Nacelle }\end{array}$} & Low speed shaft & 21 & 2.12 & 41 & 2.61 & 44 & 2.20 & 46 & 2.26 & 116 & 2.88 & 2.14 \\
\hline & Bearings & 12 & 1.21 & 27 & 1.72 & 29 & 1.45 & 31 & 1.52 & 95 & 2.36 & 1.37 \\
\hline & Gearbox & 152 & 15.34 & 218 & 13.88 & 362 & 18.11 & 362 & 17.77 & 686 & 17.06 & 14.45 \\
\hline & Mechanical brakes, etc & 3 & 0.30 & 4 & 0.25 & 6 & 0.30 & 6 & 0.29 & 10 & 2.49 & 2.64 \\
\hline & Generator & 98 & 9.89 & 130 & 8.27 & 195 & 9.75 & 195 & 9.57 & 325 & 8.08 & 7.87 \\
\hline & Variable speed electronics & 119 & 12.01 & 158 & 10.06 & 237 & 11.86 & 237 & 11.63 & 395 & 9.82 & 5.61 \\
\hline & Yaw drive $\&$ bearings & 20 & 2.02 & 39 & 2.48 & 42 & 2.10 & 44 & 2.16 & 114 & 2.83 & 1.40 \\
\hline & Main frame & 48 & 4.84 & 75 & 4.77 & 78 & 3.90 & 80 & 3.93 & 151 & 3.75 & 3.13 \\
\hline & Electrical connections & 60 & 6.05 & 80 & 5.09 & 120 & 6.00 & 120 & 5.89 & 200 & 4.97 & 1.07 \\
\hline & Hydraulic, cooling system & 18 & 1.82 & 24 & 1.53 & 36 & 1.80 & 36 & 1.77 & 60 & 1.49 & - \\
\hline & Nacelle Cover & 21 & 2.12 & 27 & 1.72 & 38 & 1.90 & 38 & 1.87 & 62 & 1.54 & 1.51 \\
\hline & Sub sum & 572 & 57.72 & 823 & 52.39 & 1,188 & 59.43 & 1,195 & 58.66 & 2,213 & 55.02 & 41.19 \\
\hline \multicolumn{2}{|c|}{ Control, Safety, Condition monitoring } & 35 & 3.53 & 35 & 2.23 & 60 & 3.00 & 60 & 2.95 & 60 & 1.49 & - \\
\hline \multicolumn{2}{|l|}{ Tower } & 147 & 14.83 & 288 & 18.33 & 301 & 15.06 & 301 & 14.78 & 649 & 16.14 & 29.44 \\
\hline \multicolumn{2}{|l|}{ Total } & 991 & 100 & 1,571 & 100 & 1,999 & 100 & 2,037 & 100 & 4,022 & 100 & 100 \\
\hline \multicolumn{2}{|l|}{ Cost per kW } & 0.66 & & 0.79 & & 0.67 & & 0.68 & & 0.80 & & \\
\hline
\end{tabular}




\section{4. 주변장치 및 유지보수의 비용 추정모델}

풍력발전기의 주변장치 비용에는 설치 지지부(foundation), 운송(transportation), 도로 신설 등 토목(road and civil works), 조립 및 설치(assembly and installation), 통전 (electrical interface/connections) 및 기타 엔지니어링 등에 소요되는 비용 등이 해당된다. 대부분의 육상용 풍력터빈의 비용요소들은 몇 개의 비용요소들을 제외하고는 해상용으로 바뀐다고 해서 크게 영향을 받지 않는다. 그러나 풍력터빈의 해상설치를 위해서는 몇 개의 부가적인 비용요소들이 추가되 어야 한다. 아직 데이터의 양이 극히 적어 추정모델의 신뢰도 가 떨어지는 편이며, 본 논문에서 소개되는 참고문헌 [3]의 비 용추정모델은 천해지역에 설치한 경우로만 국한되며, 데이터 는 주로 167 개의 $3 \mathrm{MW}$ 터빈으로 구성된 500MW 해상풍력단지 를 기초로 얻어진 것이다. 이 해상풍력단지는 해안으로부터 5 마일 떨어지고 수심이 $10 \mathrm{~m}$ 인 곳에 고정식으로 설치되어 있으 며, 터빈의 로터직경은 $90 \mathrm{~m}$ 이며 허브높이는 $80 \mathrm{~m}$ 이고, 터빈 간 앞뒤와 옆 간격은 로터직경의 7 배가 되는 $630 \mathrm{~m} \times 630 \mathrm{~m}$ 이다. 해상설치에 필요한 부가적인 비용요소들은 풍력발전기의 해 양화(Marinization), 해양 지지구조, 해상수송, 크레인 등 해 상설치를 위한 장비사용, 생산된 전기의 계통연계, 해역사용인 가 및 해역평가 등 엔지니어링, 작업자의 접근 및 안전을 위한 장비사용, Scour Protection, 보증채권 및 보험(Surety Bond and Offshore Warranty Premium), 대수선비용(Offshore Levelized Replacement Cost), 해역사용권(Offshore Bottom
Lease Cost), 해상 운용 및 유지(Offshore O\&M) 등이 있으 며 이에 대한 비용추정모델에 대해서도 참고문헌 [3]을 참고 하였는데, 이 모델에서 제시하는 비용추정 모델을 요약하면 Table 4 와 같다. Table 4 로부터 알 수 있듯이 대부분의 비용 추정모델식이 정격출력(machine rating)의 함수이며, 해상 풍력터빈의 경우 비용추정모델은 매우 단순함을 알 수 있는 데, 이는 아직 정교하고 신뢰할 만한 모델을 만들 수 있을 만 큼 데이터가 충분하지 못하여 초기버전으로 제시한 것임을 밝히고 있다.

Table 4의 추정 모델 식을 Table 2 의 풍력발전기에 적용하 면, Table 5 와 같이 주변장치의 소요비용을 추정할 수 있다. Table 5 로부터 육상에 설치되는 풍력터빈의 주변장치 설치 및 수리유지비용은 $\mathrm{kW}$ 당 약 $\$ 300$ 임에 비하여 해상풍력터빈 에서는 해상에 설치됨으로 인하여 추가적으로 비용요소가 많 이 늘어나 $\mathrm{kW}$ 당 $\$ 1,200 \sim 1,500$ 범위에 있게 됨을 알 수 있 다. 가장 비용이 큰 항목은 풍력발전기에서 생산된 전기를 모 아서 육상의 전력 공급망에 연결하는 데에 드는 통전비용으 로 육상의 경우 약 $30 \%$, 해상의 경우 약 $20 \%$ 를 차지한다. 이 비용은 풍력단지에서 육상의 전력 공급망까지의 거리, 해상 풍력단지의 경우 수심, 풍력발전기 사이의 배치거리 등에 의 해 변할 수 있으며, 이를 고려한 좀 더 정교한 비용 산출모델 이 제시될 필요가 있다. 참고로 Table 4 의 해상풍력 터빈에 비용추정모델은 육상의 전력 공급망까지의 거리 5 마일, 수심 $10 \mathrm{~m}$, 발전기간 배치거리가 $640 \mathrm{~m} \times 640 \mathrm{~m}$ 인 경우를 기초로 제시된 것이다.

Table 4. Formula for Balance of station and O\&M

\begin{tabular}{|c|c|c|c|}
\hline \multicolumn{2}{|c|}{ Cost elements } & land-based turbines & offshore-based turbines \\
\hline $\begin{array}{l}\text { Balance } \\
\text { of } \\
\text { Station }\end{array}$ & $\begin{array}{l}\text { Support structure } \\
\text { Transportation to onshore } \\
\text { Roads, and civil work } \\
\text { Turbine installation } \\
\text { Electrical interface and connection } \\
\text { Permit, engineering, and site assessment } \\
\text { Marinization } \\
\text { Port and staging equipment } \\
\text { Personnel access equipment } \\
\text { Scour protection } \\
\text { Surety bond } \\
\text { Offshore warranty premium }\end{array}$ & $\begin{array}{l}303.24^{*}\left(H^{*} A\right)^{0.4037} \\
P^{*}\left(1.581 e-5^{*} P^{2}-0.0375^{*} P+54.7\right) \\
P^{*}\left(2.17 e-06^{*} P^{2}-0.0145^{*} P+69.54\right) \\
1.965^{*}\left(H^{*} D\right)^{1.1736} \\
P^{*}\left(3.49 e-6^{*} P^{2}-0.0221^{*} P+109.7\right) \\
P^{*}\left(9.94 e-4^{*} P+20.31\right) \\
- \\
- \\
- \\
- \\
- \\
-\end{array}$ & $\begin{array}{l}300^{*} P \\
P^{*}\left(1.581 e-5^{*} P^{2}-0.0375^{*} P+54.7\right) \\
- \\
100^{*} P \\
260^{*} P \\
37^{*} P \\
13.5 \% \text { of turbine and tower costs } \\
20^{*} P \\
\$ 60,000 / \text { turbine } \\
55^{*} P \\
3 \%(I C C-\text { offshore warranty cost }) \\
15 \% \text { of turbine and tower costs }\end{array}$ \\
\hline $\begin{array}{l}\text { O\&M } \\
\text { and } \\
\text { Lease }\end{array}$ & $\begin{array}{l}\text { Levelized replacement cost } \\
\text { O\&M cost } \\
\text { land/offshore bottom lease cost }\end{array}$ & $\begin{array}{l}10.7^{*} \mathrm{P} \\
0.007^{*} \mathrm{AEP} \\
0.00108^{*} \mathrm{AEP}\end{array}$ & $\begin{array}{l}17^{*} P \\
0.02^{*} A E P \\
0.00108^{*} A E P\end{array}$ \\
\hline
\end{tabular}


Table 5. Cost prediction of Balance of station and O\&M(Costs: $\$ 1,000$ )

\begin{tabular}{|c|c|c|c|c|c|c|c|c|c|c|c|}
\hline \multirow{2}{*}{\multicolumn{2}{|c|}{ Cost elements }} & \multicolumn{4}{|c|}{ land-based turbines } & \multicolumn{6}{|c|}{ offshore-based turbines } \\
\hline & & \multicolumn{2}{|c|}{$\begin{array}{c}\text { NREL } \\
1.5 \mathrm{MW}\end{array}$} & \multicolumn{2}{|c|}{$\begin{array}{l}\text { Model A } \\
2.0 \mathrm{MW}\end{array}$} & \multicolumn{2}{|c|}{$\begin{array}{l}\text { NREL } \\
3.0 \mathrm{MW}\end{array}$} & \multicolumn{2}{|c|}{$\begin{array}{l}\text { Model B } \\
3.0 \mathrm{MW}\end{array}$} & \multicolumn{2}{|c|}{$\begin{array}{c}\text { OC3 } \\
5.0 \mathrm{MW}\end{array}$} \\
\hline $\begin{array}{l}\text { Balance } \\
\text { of } \\
\text { Station }\end{array}$ & $\begin{array}{l}\text { Support structure } \\
\text { Transportation to onshore } \\
\text { Roads, and civil work } \\
\text { Turbine installation } \\
\text { Electrical interface and connection } \\
\text { Permit, engineering, and site assessment } \\
\text { Marinization } \\
\text { Port and staging equipment } \\
\text { Personnel access equipment } \\
\text { Scour protection } \\
\text { Surety bond } \\
\text { Offshore warranty premium }\end{array}$ & $\begin{array}{r}45.8 \\
51.0 \\
79.0 \\
38.6 \\
126.6 \\
32.7 \\
- \\
- \\
- \\
- \\
- \\
-\end{array}$ & $\begin{array}{r}11 \% \\
12 \% \\
19 \% \\
9 \% \\
30 \% \\
8 \% \\
-\end{array}$ & $\begin{array}{r}59.9 \\
85.9 \\
98.4 \\
64.4 \\
158.9 \\
44.6 \\
- \\
- \\
- \\
- \\
- \\
-\end{array}$ & $\begin{array}{r}10 \% \\
14 \% \\
16 \% \\
10 \% \\
26 \% \\
7 \% \\
- \\
- \\
- \\
- \\
- \\
-\end{array}$ & $\begin{array}{r}900.0 \\
253.5 \\
- \\
300.0 \\
780.0 \\
111.0 \\
269.9 \\
60.0 \\
60.0 \\
165.0 \\
303.0 \\
299.9\end{array}$ & $\begin{array}{r}23 \% \\
6 \% \\
- \\
8 \% \\
20 \% \\
3 \% \\
7 \% \\
2 \% \\
2 \% \\
4 \% \\
8 \% \\
8 \%\end{array}$ & $\begin{array}{r}900.0 \\
253.5 \\
- \\
300.0 \\
780.0 \\
111.0 \\
274.0 \\
60.0 \\
60.0 \\
165.0 \\
153.0 \\
305.0\end{array}$ & $\begin{array}{r}25 \% \\
7 \% \\
- \\
8 \% \\
21 \% \\
3 \% \\
8 \% \\
2 \% \\
2 \% \\
5 \% \\
4 \% \\
8 \%\end{array}$ & $\begin{array}{r}1,500.0 \\
1,312.0 \\
- \\
500.0 \\
1,300.0 \\
185.0 \\
543.0 \\
100.0 \\
60.0 \\
275.0 \\
303.0 \\
603.0\end{array}$ & $\begin{array}{r}21 \% \\
18 \% \\
7 \% \\
18 \\
3 \% \\
8 \% \\
1 \% \\
1 \% \\
4 \% \\
4 \% \\
8 \%\end{array}$ \\
\hline $\begin{array}{l}\text { O\&M } \\
\text { and } \\
\text { Lease }\end{array}$ & $\begin{array}{l}\text { Levelized replacement cost } \\
\text { O\&M cost } \\
\text { land/offshore bottom lease cost }\end{array}$ & $\begin{array}{r}16.1 \\
30.7 \\
4.7 \\
\end{array}$ & $\begin{array}{l}4 \% \\
7 \% \\
1 \%\end{array}$ & $\begin{array}{r}21.4 \\
72.8 \\
11.2 \\
\end{array}$ & $\begin{array}{r}3 \% \\
12 \% \\
2 \% \\
\end{array}$ & $\begin{array}{r}51.0 \\
297.7 \\
16.1\end{array}$ & $\begin{array}{l}1 \% \\
8 \% \\
0 \% \\
\end{array}$ & $\begin{array}{r}51.0 \\
207.9 \\
11.2 \\
\end{array}$ & $\begin{array}{l}1 \% \\
6 \% \\
0 \% \\
\end{array}$ & $\begin{array}{r}85.0 \\
366.6 \\
19.8 \\
\end{array}$ & $\begin{array}{l}1 \% \\
5 \% \\
0 \%\end{array}$ \\
\hline \multicolumn{2}{|r|}{ Total } & 425.2 & $100 \%$ & 617.6 & $100 \%$ & 3,867 & $100 \%$ & 3,632 & $100 \%$ & 7,153 & $100 \%$ \\
\hline & Cost per kW & \multicolumn{2}{|c|}{0.283} & \multicolumn{2}{|c|}{0.309} & \multicolumn{2}{|c|}{1.289} & \multicolumn{2}{|c|}{1.211} & \multicolumn{2}{|c|}{1.431} \\
\hline
\end{tabular}

\section{5. 연간 순에너지 생산량의 계산}

연간 에너지 생산량은 주어진 년 평균 풍속을 바탕으로 계 산되며, 풍속의 분포는 Weibull 분포를 갖는 것으로 가정하 여 다음 식으로 계산된다.

$$
A E P_{n e t}=\sum A(1-B)(1-C) P(v) f(v) \cdot 8760
$$

$\mathrm{AEP}_{\text {net }}=$ 연간 순에너지 생산량 $(\mathrm{kWh} /$ year $)$

$$
\begin{aligned}
\mathrm{A} & =\text { 가동율 } \\
\mathrm{B} & =\text { soiling losses } \\
\mathrm{C} & =\text { array losses }
\end{aligned}
$$

$\mathrm{f}(\mathrm{v})=$ Weibull 분포에서 풍속이 $\mathrm{v}$ 가 될 확률

$\mathrm{P}(\mathrm{v}) \quad=$ 풍속 $\mathrm{v}$ 에서의 생산전력 $(\mathrm{kW})$

$=\frac{1}{2} \eta C_{p} \rho \frac{\pi D^{2}}{4} v^{3}$

$\eta \quad=$ 터빈의 효율

$C_{p} \quad=$ 로터의 출력계수로서 로터의 설계 등에 영향을 받음

$\rho=$ 공기의 밀도

$D=$ 터빈 날개 직경

$v \quad=$ 허브 높이에서의 풍속
여기에서 터빈의 효율은 다음과 같이 계산된다.

$$
\eta=\left[\frac{P}{P_{\text {rated }}}-C+L \frac{P}{P_{\text {rated }}}+Q\left(\frac{P}{P_{\text {rated }}}\right)^{2}\right] /\left(\frac{P}{P_{\text {rated }}}\right)
$$

$$
\mathrm{P}=\text { 풍속 } \mathrm{V} \text { 에서의 출력 }
$$

$\mathrm{P}_{\text {rated }}=$ 정격 출력

$\mathrm{C}$ = 전력의 크기에 상관없는 전력 손실량

$\mathrm{L} \quad=$ 전력의 크기에 선형적으로 비례하는 전력 손실량

$\mathrm{Q}=$ 전력의 크기 자승에 비례하는 전력 손실량

풍력발전기가 설치된 지역의 공기밀도는 고도에 따라 달라 지며 다음 식에 의해 계산된다.

$$
\rho=\frac{101300^{*}\left[1-\left(\frac{0.0065^{*} \text { altitude }}{288}\right)^{\frac{9.80665}{0.0065^{*} 287.15}}\right]}{287.15^{*}\left(288-0.0065^{*} \text { altitude }\right)}
$$

또한 허브 높이에서의 풍속은 $50 \mathrm{~m}$ 높이의 풍속으로부터 다음과 같이 계산된다.

$$
v=\left(\frac{\text { hubheight }}{50}\right)^{\text {shear }} * 50 \text { m wind speed }
$$


여기에서 shear는 Power law shear exponent를 나타낸다. 연간 순에너지 생산량은 연간 발전량에 가동률(Availability) 을 곱하여 계산되는데, 오늘날의 풍력터빈은 신뢰성이 높아 져서 대개 $95 \%$ 이상의 가동률을 갖는다. Fig. 2는 식 (3)에 의

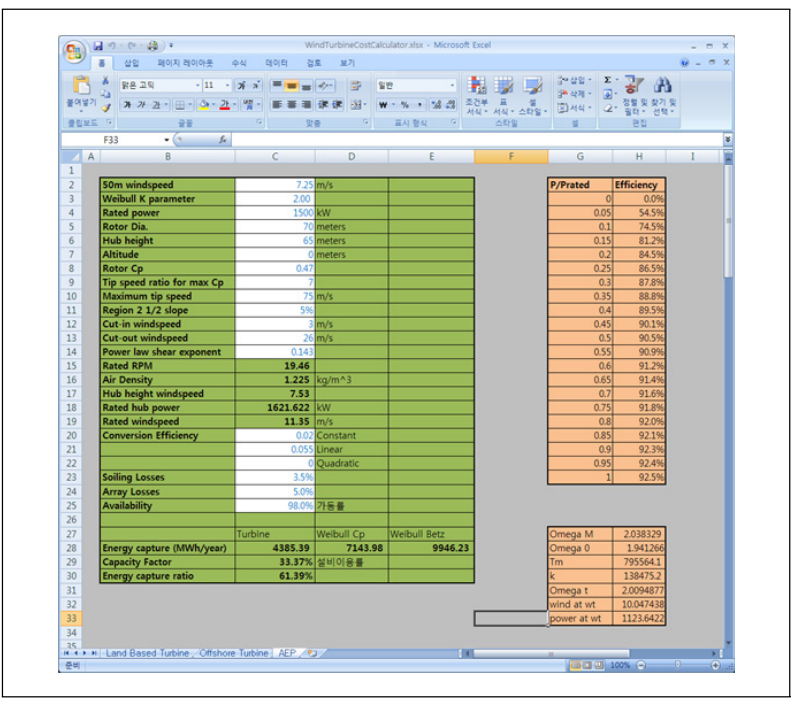

Fig. 2 An example of spreadsheet program for annual energy cost
거하여 풍력발전기의 순에너지 생산량을 계산하는 MS-EXCEL 기반의 프로그램을 육상용 $1.5 \mathrm{MW}$ 풍력발전기에 적용한 결과 를 보여주고 있다.

\section{6. 에너지 비용 산출 및 결과 분석}

앞에서 서술된 연간 순에너지 생산량 계산방법과 NREL의 풍력터빈 구성품의 비용추정 모델과 주변장치(Balance of Station)의 설치 및 유지보수에 대한 비용추정 모델을 사용 하여 MS-EXCEL 기반의 에너지비용 산출프로그램을 완성 하였다. 이를 이용하여 $1.5 \mathrm{MW}$ 육상용 풍력발전기, 고정식 $3.0 \mathrm{MW}$ 해상용 풍력발전기를 대상으로 경제성을 평가하여 보았다. 산출한 결과를 Table 6에 비교하여 정리하였는데 중 요한 사항은 다음과 같다.

1) 풍력발전기의 효율성 측면에서 capacity factor를 비교하 여 볼 때 육상용(33.37\%)에 비하여 해상용(38.23\%)이 더 큰 효율성을 갖는다.

Table 6. Cost of energy of wind turbines

\begin{tabular}{l|c|c|c}
\hline Design parameter & $\begin{array}{c}\text { NREL 1.5 MW } \\
\text { (land based) }\end{array}$ & $\begin{array}{c}\text { NREL 3.0 MW } \\
\text { (offshore based) }\end{array}$ & Ratio \\
\hline Machine rating $(\mathrm{kW})$ & 1,500 & 3,000 & 2.0 \\
\hline Rotor diameter $(\mathrm{m})$ & 70 & 90 & 1.3 \\
\hline Hub height $(\mathrm{m})$ & 65 & 80 & 1.2 \\
\hline Wind speed @ $50 \mathrm{~m}(\mathrm{~m} / \mathrm{s})$ & 7.25 & 8.1 & 0.8 \\
\hline Rated RPM & 20.46 & 15.92 & 1.1 \\
\hline Rated wind speed $(\mathrm{m} / \mathrm{s})$ & 11.35 & 12.10 & 2.3 \\
\hline Energy capture $(\mathrm{MWh} /$ year) & $4,385.39$ & $10,046.73$ & 1.1 \\
\hline Capacity $(\%)$ & 33.37 & 38.23 & 2.3 \\
\hline Turbine capital cost $(\$ 1,000)$ & 991 & 2,269 & 7.4 \\
\hline Balance of station $(\$ 1,000)$ & 374 & 2,781 & - \\
\hline Offshore warranty premium $(\$ 1,000)$ & 0 & 300 & 3.9 \\
\hline Subtotal: Initial capital cost $(\$ 1,000)$ & 1,364 & 5,350 & 2.0 \\
\hline Installed cost per $\mathrm{kW}(\$)$ & 910 & 1,783 & 1.1 \\
\hline Turbine capital per kW $(\$)$ & 660 & 756 & 3.2 \\
\hline Levelized replacement cost per year $(\$)$ & 16 & 51 & 6.5 \\
\hline O\&M per year $(\$)$ & 31 & 201 & 2.2 \\
\hline Land/Bottom lease cost $(\$)$ & 5 & 11 & 1.0 \\
\hline Fixed charge rate $(\%)$ & 11.85 & 11.85 & 1.8 \\
\hline COE $(\$ / \mathrm{kWh})$ & 0.0486 & 0.0893 & \\
\hline
\end{tabular}


2) 터빈제작에 드는 자산비용은 해상용이 육상용의 2.3 배로서 정격출력의 비인 2에 비해 조금 큰 편이나, 주변장치비용의 비는 7.4로서 크게 차이가 난다. 육상용의 경우 터빈제작비 용 $(\$ 991,000)$ 에 비하여 주변장치비용은 $\$ 374,000$ 로서 터 빈제작비요의 약 $38 \%$ 인데 반하여, 해상용의 경우 터빈 제 작비용 $(\$ 2,269,000)$ 보다도 주변장치 비용 $(\$ 2,781,000)$ 이 더 크며, 따라서 해상용의 경우 주변장치 비용을 낮출 수 있어야 경제성을 확보할 수 있다.

3) 결론적으로 $\mathrm{kWh}$ 당 에너지비용은 육상용은 $\$ 0.0486$, 해 상용은 $\$ 0.0893$ 으로서 해상용의 에너지 비용이 육상용의 약 1.8 배이다.

\section{7. 부유식 풍력발전기의 지지구조물에 대한 비용 추정}

풍력발전설비를 위한 자산비용 중에서 터빈 비용이 가장 큰 비중을 차지한다. 부유식 해상풍력의 경우의 터빈비용은 기존의 육상터빈이나 고정식의 해상터빈 비용과 유사하다고 볼 수 있다. 또한, 변전소의 설치, 내부 전선망, 환경영향평 가, 설계 및 프로젝트 운영비는 전체 자산비용 중에서 적은 부분이며 기존의 풍력발전설비와 크게 다르지 않을 것이다. 아직까지 부유식 해상풍력 발전시스템에 대하여는 기술에 대 한 불확실성, 설치사례의 부족 등으로 예측이 불가능하나, 해 상환경이 더욱 열악하고, 해안으로부터 먼 거리에 있으며 플 랫폼도 안정성이 취약하므로 부유식 풍력발전설비를 위한 주 변장치, 설치 및 $\mathrm{O} \& \mathrm{M}$ 에 들어가는 비용이 더욱 증가할 것임 에는 틀림이 없다. 여기서는 개발된 프로그램을 OC3의 $5 \mathrm{MW}$ 터빈에 적용하여 부유식 해상풍력 발전설비를 고정식 해상풍 력 발전설비와 비교해 볼 때 가장 큰 차이를 보이는 support structure에 대하여 제작비용을 추정하고, 이를 NREL에서
제시하는 비용추정모델을 사용하여 추정한 육상 및 고정식 해상풍력 발전설비의 제작비용과 비교하여 보기로 한다.

OC3-Hywind의 support structure는 크게 원형실린더 모양의 spar 구조물과 계류선으로 구성된다. spar 구조물의 건조비는 이와 유사한 해양플랫폼의 건조 실적이 많은 국내 대형사의 임원들의 자문을 통하여 톤당 약 $\$ 5,000$, 계류선은 톤당 약 $\$ 2,000$ 임을 확인하였다. 최근의 mild steel 톤당 가 격은 $\$ 600$ 700이며, 구조물 제작이 비교적 쉬운 대형 유조 선의 경우 톤당 건조비가 약 $\$ 2,000$ 정도임을 고려할 때 이는 매우 높은 제작단가이나 원형실린더인 경우 곡가공이 어려워 건조비가 높다고 한다. 이를 적용하여 보면 OC3의 support structure 건조비는 아래와 같이 추정된다. 또한, 밸러스트 용 콘크리트는 시중에서 사용되는 강도 $180 \mathrm{~kg}$ 의 콘크리트인 경우 약 60,000 원 $/ \mathrm{m}^{3}$ 으로 알려져 있으며 비중 2.3 톤 $/ \mathrm{m}^{3}$ 을 고려하고 환율 1,200 원 $/ \$$ 을 고려하면 톤당 가격이 약 $\$ 22$ 으 로 계산되어 이를 적용한다.

spar 구조물 $=879.840$ 톤 $\times \$ 5,000 /$ 톤 $=\$ 4,399,200$

계류선 $=902 \mathrm{~m} \times 77.7 \mathrm{~kg} / \mathrm{m} \times \$ 2 / \mathrm{kg} \times 3 \mathrm{set}=\$ 420,512$ 콘크리트 밸러스트 $=3,629.910$ 톤 $\times \$ 22 /$ 톤 $=\$ 79,858$ 합계 $=\$ 4,899,570$

NREL에서 제안한 추정식에 따라 고정식의 support structure 제작비는 정격출력 $1 \mathrm{~kW}$ 당 $\$ 300$ 로 다음과 같이 추정된다.

$\$ 300 / \mathrm{kW} \times 5,000 \mathrm{~kW}=\$ 1,500,000$

위로부터 알 수 있듯이 OC3-Hywind의 경우 부유식 support structure의 제작비는 spar 구조물의 제작비가 대부분을 차 지하며, 고정식에 비하여 3.27 배가 된다. 이는 앞으로 부유 식 풍력에 대한 수요가 많아지고, spar 플랫폼 구조물에 대한 저렴한 건조공법이 개발되면 낮아질 수 있다. 참고로 유조선

Table 7. Cost of energy of wind turbines at rated wind speed, $8 \mathrm{~m} / \mathrm{s}$

\begin{tabular}{l|c|c|c}
\hline Design parameter & Land & Offshore (fixed) & Offshore (floating) \\
\hline Turbine capital cost $(\$ 1000)$ & 4,022 & 4,565 & 4,565 \\
\hline Balance of station cost $(\$ 1000)$ & 2,320 & 5,535 & 8,757 \\
\hline Lease and O\&M cost $(\$ 1000 / \mathrm{yr})$ & 202 & 471 & 471 \\
\hline COE $(\$ / \mathrm{kWh})$ & 0.052 & 0.095 & 0.116 \\
\hline
\end{tabular}


의 건조단가인 $\$ 2,000 /$ 톤을 적용하면 spar 구조물의 건조비 는 $\$ 1,759,680$, 플랫폼의 총 건조비는 $\$ 2,260,050$ 으로 NREL 의 추정식에 따른 제작비의 약 1.5 배가 된다.

Table 7에 OC3의 5MW 터빈을 육상에 설치했을 경우와 해 상에 고정식과 부유식으로 설치했을 경우에 대하여 에너지비 용을 산출한 결과를 정리하였다. 이를 보면 부유식 해상풍력 의 에너지비용은 $\mathrm{kWh}$ 당 $\$ 0.116$ 으로서 육상용의 비용 $\$ 0.052$ 에 비하여 약 2.2 배, 고정식 해상풍력의 비용 $\$ 0.095$ 에 비하 여 약 1.2 배가 됨을 알 수 있다. 그러나 이는 육상에서나 해상

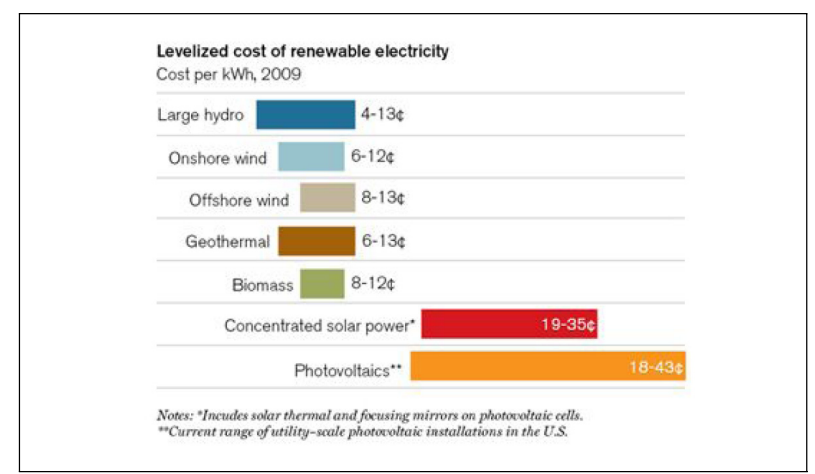

Fig. 3 Levelized cost of renewable electricity ${ }^{(5)}$

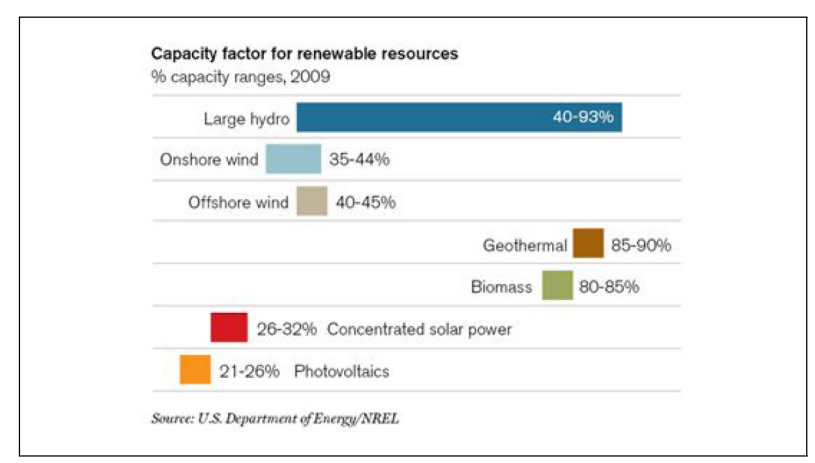

Fig. 4 Capacity factor for renewable resources ${ }^{(5)}$
에서의 정격풍속을 $8 \mathrm{~m} / \mathrm{s}$ 로 가정하고 계산을 수행한 결과로 서, 일반적으로 육상에 비하여 해상에서의 바람이 질이 좋고 정격풍속이 높다는 것을 감안한다면 이러한 비용의 차이는 줄어 들 수 있다. 예로서 Table 8에서 보듯이 육상에서의 정 격풍속을 $7 \mathrm{~m} / \mathrm{s}$ 으로 가정하고 에너지비용을 비교해 보면 $\mathrm{kWh}$ 당 5.2센트에서 6.2 센트로 높아져 부유식 해상풍력의 에너지 비용이 약 2.2 배에서 1.9 배로 낮아짐을 알 수 있다.

참고로 위에서 계산된 에너지비용을 Fig. 3에서 보는 바 와 같이 2009년 기준의 신재생에너지별 에너지비용자료[5] 와 비교해 보면 육상용과 해상용 모두 자료에서 제시한 범 위 안에 있음을 알 수 있다. 또한 Fig. 4 에는 신재생에너지 별 capacity factor 값의 범위를 보여주고 있는데, capacity factor 값의 범위가 해상풍력의 경우 40-45\%, 육상풍력의 경우 35-44\%로서 해상풍력의 capacity factor가 더 크며 Table 8에 보인 capacity factor의 값들도 대략 그 범위에 있 음을 알 수 있다.

\section{8. 결 론}

본 연구에서는 미국 NREL의 연구결과로서 발표된 축척에 따른 풍력발전 비용 추정모델을 소개하고, 이를 국내외 육상 및 해상풍력발전시스템에 적용하여 그 결과를 분석하였다. 본 연구를 통하여 수행된 연구내용을 요약하면 다음과 같다.

(1) 풍력발전기의 주요 부품에 대해 비용추정모델과 풍력발 전기의 주변장치 및 운영유지 비용에 대한 추정모델을 국 내외 풍력발전기 5 종에 대해 적용하여 보았다.

(2) 풍력발전기의 주요부품, 주변장치 및 유지보수 비용 산정

Table 8. 육상에서의 정격풍속 저감을 고려한 OC-3 풍력발전기에 대한 COE 비교

\begin{tabular}{|c|c|c|c|}
\hline Design parameter & Land & Offshore (fixed) & Offshore (floating) \\
\hline Rated wind speed $(\mathrm{m} / \mathrm{s})$ & 7 & 8 & 8 \\
\hline Capacity factor & 34.0 & 41.9 & 41.9 \\
\hline AEP (MWh) & 14,886 & 18,332 & 18,332 \\
\hline Turbine capital cost $(\$ 1000)$ & 4,022 & 4,565 & 4,565 \\
\hline Balance of station cost $(\$ 1000)$ & 2,320 & 5,535 & 8,757 \\
\hline Lease and $O \& M$ cost $(\$ 1000 / y r)$ & 202 & 471 & 471 \\
\hline COE (\$/kWh) & 0.062 & 0.095 & 0.116 \\
\hline
\end{tabular}


을 위해 MS-Excel 기반의 spreadsheet program을 개발 하여 적용하고, 결과에 대한 타당성을 검토해 보았다.

(3) 부유식 풍력발전시스템의 지지구조물에 대한 비용추정 모델을 제시하고, 육상용 및 고정식 해상용 들과 $\mathrm{COE}$ 를 비교하여 보았다.

이상의 연구결과를 토대로 풍력발전시스템의 초기 경제성 분석에 유용하게 활용할 수 있는 자료를 확보한 것으로 판단 된다.

\section{후 기}

본 연구는 지식경제부 산하 산업기술연구회의 지원으로 한 국기계연구원에서 수행 중인 주요사업 연구과제(과제명: 능 동형 위험관리 기반기술개발)의 결과 중 일부임을 밝힙니다.

\section{정 태 영}

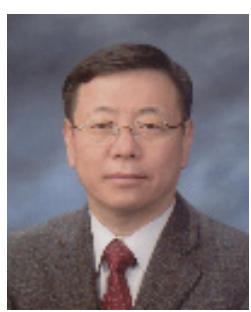

1975년 서울대학교 조선공학과 공학사 1977년 서울대학교 조선공학과 공학석사 1987년 MIT 해양공학과 공학박사

현재 한국기계연구원 시스템다이나믹스연구실 연구위원 (E-mail : tychung@kimm.re.kr)

\section{임 채 환}

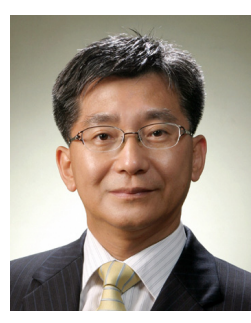

1980년 서울대학교 조선공학과 공학사 1984년 서울대학교 조선공학과 공학석사 1993년 미시건대학교 조선해양공학과 공학박사

\section{References}

[1] 하정우, 김수덕, "대관령 풍력단지의 풍력발전량 및 경제성 분석”, 에너지공학 제14권 제2호, 2005.

[2] S. Krohn, P.E. Morthorst, and S. Awerbuch, The Economics of Wind Energy, EWEA report, March 2009.

[3] L. Fingersh, M. Hand, and A. Laxon, "Wind Turbine Design Cost and Scaling Model", Technical report NREL/TP500-40566, December 2006.

[4] Maria Isabel Blanco, "The Economics of wind energy", Renewable and Sustainable Energy Reviews 13, pp. 1372-1382, 2009.

[5] David Rotman, "Praying for an energy miracle", Technology Review, Vol. 114/No. 2, pp. 46-52, MIT, 2011.

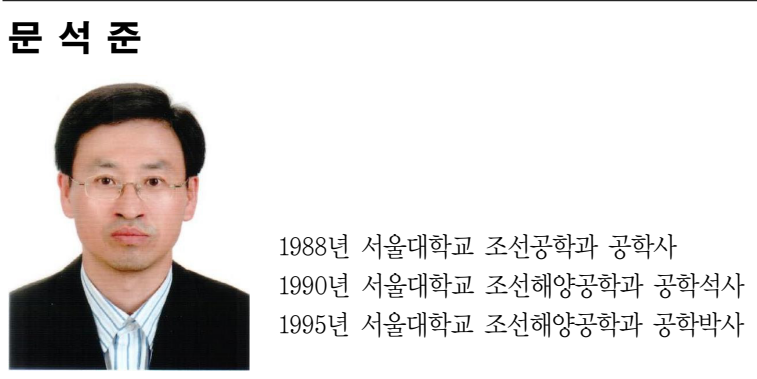

현재 한국기계연구원 시스템다이나믹스연구실 책임연구원 (E-mail : sjmoon@kimm,re.kr)

현재 한국기계연구원 시스템신뢰성연구실 책임연구원

(E-mail : cwrim@kimm.re.kr) 